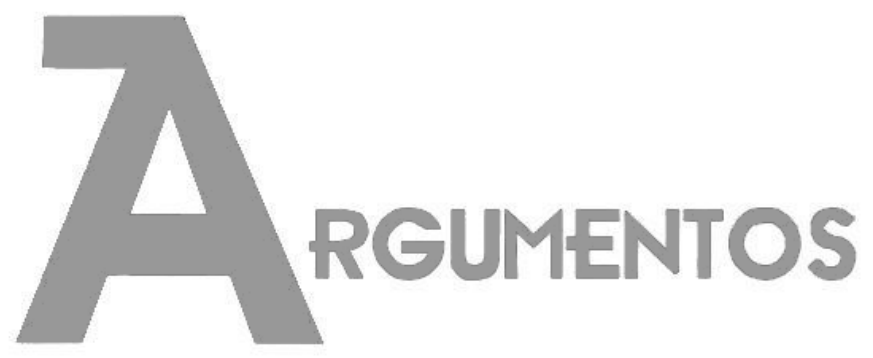

Vol. 16, n. 1, jan./jun. 2019 ISSN: 2527-2551 (online)

http://www.periodicos.unimontes.br/argumentos

\title{
Os desafios para a economia solidária em uma sociedade do consumo
}

\author{
Ednalva Felix das Neves ${ }^{1}$ \\ Gabriela Gonzales Mezzacappa ${ }^{2}$ \\ Valter Palmieri Júnior ${ }^{3}$
}

Recebido em: 29/08/2018

Aprovado em: 14/03/2019

Resumo: A constituição da sociedade do consumo foi um fenômeno fomentado pela dinâmica de acumulação do sistema capital ista, fazendo com que a lógica da exploração fosse além da produção de mercadorias e atingisse, também, a esfera do consumo. Na sociedade atual, o consumo vai além da satisfação de necessidades: ele é um diferenciador entre as pessoas e as classes sociais. O capitalismo se apropria das críticas e alternativas a esta lógica, submetendoas a sua própria dinâmica e utilizando-as em seu favor, impedindo uma efetiva mudança desta lógica. A proposta de um modelo de consumo conscientee solidário, da Economia Solidária, tem se apresentado como uma alternativa importante, já que ela vai além da mudança de hábitos individuais e pontuais - ela defende uma total mudança de sociedade, em que os valores sejam repensados e reconstruídos, a partir da perspectiva humana e de sustentabilidade, e não da geração de lucro. Assim, o objetivo deste artigo é discutir o papel do consumo para a Economia Solidária, que resulta na proposta do consumo solidário e consciente.

Palavras-Chaves: Economia Solidária; Sociedade do Consumo; Consumo Consciente e Solidário.

\section{Desafíos para la economía solidaria en una sociedad del consumo}

\footnotetext{
${ }^{1}$ Doutora em Desenvolvimento Econômico pela Universidade Estadual de Campinas - Campinas, Brasil. Pós-doutoranda no Programa de Pós-Graduação em Economia e Desenvolvimento da Universidade Federal de Santa Maria - Santa Maria, Brasil. E-mail: ednalvafelix@gmail.com. ORCID: https://orcid.org/0000-0002-8862-1674.

2 Mestre em Ciência, Tecnologia e Sociedade pela Universidade Federal de São Carlos -São Carlos, Brasil. Professora das Faculdades Integradas Einstein de Limeira. E-mail: psi.ggm@gmail.com. ORCID: https://orcid.org/0000-0002-3329-6106.

${ }^{3}$ Mestre e Doutor em Desenvolvimento Econômico pela Universidade Estadual de Campinas -Campinas, Brasil. E-mail:< valterpalmierijr@yahoo.com.br>. ORCID: https://orcid.org/0000-0002-6369-5482.
} 
Resumen: La creación de la sociedad del consumo fue un fenómeno fomentado por la dinámica de acumulación del sistema capital ista, que hizo con que la lógica de la explotación fuera más allá de la producción de mercancías y al canzara, también, la esfera del consumo. En la sociedad actual, el consumo va más allá de la satisfacción de necesidades: él es un diferenciador entre las personas y las clases sociales. El capital ismo se apropia de las críticas y al ternativas a esta lógica, sometiéndolas a su propia dinámica y utilizándolas en su favor, impidiendo un efectivo cambio de esta lógica. La propuesta de un modelo de consumo consciente y solidario, de la Economía Solidaria, se ha presentado como una al ternativa importante, ya que va más allá del cambio de hábitos individuales y puntuales - defiende un total cambio de sociedad, en que los valoressean repensados y reconstruidos, desde la perspectiva humana y de sostenibilidad, y no de la generación de ganancia. Así, el objetivo de este artículo es discutir el papel del consumo para la Economía Solidaria, que resulta en la propuesta del consumo solidario y consciente.

Palabras-claves: Economía Solidaria. Sociedad del Consumo. Consumo Consciente y Solidario.

\section{The challenges for the solidarity economy in a consumer society}

Abstract: The creation of the Consumer Society was a phenomenon that was fomented by the dynamics of accumulation of the Capitalist System, resulting in the logic of exploitation beyond the production of consumer goods, and reaching, also, the sphere of consumption. In our current society, consumption goes beyond satisfying needs: it is a differentiator between people and social classes. The capitalism appropriates criticisms and alternatives to this logic, subjecting them to its own dynamics and using them in its favor, stopping an effective change of this logic. The proposal of creation of a model of conscious and solidarity consumption, in the Solidarity Economy, has been as important al ternative, because it goes beyond the individual and punctual changes - it advocates a total change of society, in which values are rethought and rebuild, based on a notion that the human and sustainabil ity are in the firstplace, and not the generation of profit. Thus, the objective of this article is to discuss the issue of consumption for the Solidarity Economy, which results in the proposed of the solidarity and conscious consumption. Keywords: Solidarity Economy. Consumer Society. Conscious and Solidarity Consumption.

\section{Introdução}

A lógica do sistema capitalista de produção tem como imperativo maior a geração de lucro e acumulação de capital que, por seu caráter dinâmico e contraditório, desencadeia continuamente uma série de transformações no decorrer de seu desenvolvimento, e uma delas é o processo de mercantilização da "vida social". Assim, cada vez mais o capitalismo necessita, para sua contínua valorização de riqueza, penetrar no sistema cultural e ideológico da sociedade, transformando-a a partir desta sua lógica perversa e destrutiva. É o que se pode dizer, por exemplo, com relação à questão do consumo de bens, que deveria ter como objetivo satisfazer as necessidades das pessoas, mas que passou a ser cultuado como símbolo de status, prestígio social e 
Artigo | Os desafios para a economia solidáría em uma sociedade do consumo (NEVES, Ednalva Felix das; MEZZACAPPA, Gabriela Gonzales; PALMIERI JÚNIOR, Valter)

diferenciação - como se criasse uma classe superior de pessoas, capazes de se diferenciar por meio dos bens que consome (marcas e quantidade).

Por outro lado, este processo criou (e tem mantido) uma classe de excluídos, marcados pelo empobrecimento e exclusão econômica e social - são pessoas que não conseguem adquirir o mínimo para um consumo capaz de lhes fornecer uma condição digna de vida (alimentação, itens de vestimenta, moradia, saúde, educação, etc.).

As consequências históricas desse processo excludente e polarizador serviram como base para o surgimento das alternativas de sobrevivência com base na Economia Solidária. Tendo surgido, em princípio, como iniciativas dos próprios excluídos, que buscavam criar alternativas de sobrevivência, logo se transformou em um movimento social - o movimento da Economia Solidária. Enquanto movimento social, a Economia Solidária ganhou "voz" e passou a questionar os fatores que levavam ao surgimento da exclusão social, concluindo que o cerne do problema era o sistema capitalista de produção. Assim, o movimento social da Economia Solidária passou a defender valores que colocam o ser humano no centro das preocupações, definindo-se como uma forma alternativa de produção, comercialização, consumo e distribuição de bens, que pleiteia, como essência, a valorização do ser humano na sua plenitude, e não do capital. E por se apresentar como uma lógica alternativa ao processo de produção capitalista e, para tal, defender princípios que se diferem daqueles praticados por este, a Economia Solidária apresenta uma proposta alternativa, também, para a questão do consumo.

Neste sentido, o objetivo deste trabalho é discutir o papel do consumo para a Economia Solidária, partindo da análise do atual estágio de desenvolvimento capitalista, em que predomina a sociedade do consumo para, em seguida, refletir sobre a proposta do consumo solidário e consciente, apresentada pela Economia Solidária como uma alternativa a este modelo dominante.

É importante destacara importância, tanto de refletir sobre a dinâmica predatória da sociedade do consumo, quanto mostrar a busca por alternativas para a construção de uma sociedade sustentável e mais igualitária, especialmente, tendo como base um movimento que vem se esforçando para construir uma alternativa de sociedade que se contraponha ao modelo excludente e polarizador capitalista.

O trabalho está dividido em três seções: na primeira será apresentada a discussão sobre a concepção, os objetivos e princípios da Economia Solidária, numa reflexão sobre 
Artigo | Os desafios para a economia solidáría em uma sociedade do consumo (NEVES, Ednalva Felix das; MEZZACAPPA, Gabriela Gonzales; PALMIERI JÚNIOR, Valter)

como ela se contrapõe à norma vigente da sociedade capitalista. Esta discussão serve como base para a segunda seção, em que o foco é o modelo de consumo predatório da sociedade do consumo no capitalismo. Na terceira seção será discutida a proposta alternativa de consumo consciente e solidário da Economia Solidária.

\section{A Economia Solidária como alternativa ao desemprego à sociedade capitalista}

O fenômeno que recebeu o nome de Economia Solidária no Brasil surgiu no final do século XX, motivado pelo aumento da pobreza e da miserabilidade de uma parcela significativa da população - fator que já era historicamente conhecido na sociedade brasileira (causado pela concentração de renda e riquezas). Este quadro foi agravado pelas mudanças ocorridas no mercado de trabalho brasileiro, que ocasionaram aumento do desemprego e precarização do trabalho, na década de 1980. Tais fatores contribuíram para piorar a situação de vulnerabilidade social daqueles que já viviam em situação de vulnerabilidade, e ameaçavam incluir nela, uma parcela de trabalhadores que se tornavam desempregados, devido à quebra e fechamento das fábricas, motivado pela crise (NEVES, 2016).

Existem diversas tentativas de definir Economia Solidária, mas todas elas têm em comum o fato de defenderem princípios e práticas que valorizam o ser humano e a sociedade, ao invés do capital. O professor Paul Singer - um dos pioneiros na construção do conceito, bem como na análise e entendimento das iniciativas de Economia Solidária no Brasil - define a Economia Solidária como:

Conjunto de experiências coletivas de trabalho, produção, comercialização e crédito, organizadas por princípios solidários e que aparecem sob diversas formas: cooperativas e associação de produtores, empresas autogestionárias, bancos comunitários, clubes de troca e diversas organizações populares e urbanas e rurais (SINGER, 2000, p.13).

Esta definição é pautada na realidade das iniciativas, uma vez que as descreve. A definição do professor Antônio Cruz assemelha-se à de Singer:

O conjunto das iniciativas econômicas associativas nas quais (a) o trabal ho, (b) a propriedade de seus meios de operação (de produção, de consumo, de crédito etc.), (c) os resultados econômicos do empreendimento, (d) os conhecimentos acerca de seu funcionamento e (e) o poder de decisão sobre 
as questões a ele referentes são compartilhados por todos aqueles que dele participam diretamente, buscando-se relações de igualdade e de solidariedade entre seus partícipes (CRUZ, 2006, p. 89).

Nesta mesma linha, destaca-se, ainda a definição de Laville e Gaiger:

Coletivos degeração de renda, cantinas populares, cooperativas de produção e comercialização, empresas de trabalhadores, redes e clubes de troca, sistemas de comércio justo e de finanças, grupos de produção ecológica, comunidades produtivas autóctones, associações de mulheres, serviços de proximidade, etc. (LAVILLE e GAIGER, 2009, p. 162).

De acordo com as definições, é possível classificar as experiências de Economia Solidária em três segmentos ${ }^{4}$ relacionados: i) ao processo produtivo, por meio de cooperativas e associações de produção, empresas recuperadas pelos trabalhadores, etc.; ii) ao processo de comercialização, por meio das cooperativas e associações de comercialização, as redes e clubes de troca, os sistemas de comércio justo, os coletivos de consumidores, os bancos de tempo, etc.; iii) às finanças, representadas por redes de finanças, bancos comunitários, cooperativas de crédito, etc. (NEVES, 2016).

As definições retratam a busca dos trabalhadores por gerar sua própria sobrevivência, em que as alternativas de trabalho e renda se davam através de: formação de cooperativas e associações de catadores - por meio das quais os trabalhadores buscavam, dentre os detritos urbanos, encontrar possíveis materiais que poderiam ser vendidos para a reciclagem (plásticos, vidros, papel, etc.); atividades de costuras, bordados, crochês, artesanatos, etc.; produção de alimentos - panificação, fabricação de doces, salgados, etc.; recuperação de empresas em vias de falência; dentre outras. Por meio destas atividades, os trabalhadores conseguiam gerar alguma renda, capaz de assegurar sua sobrevivência e de suas famílias (NEVES, 2016).

A geração de trabalho e renda é garantida na Economia Solidária pelo atendimento ao princípio de que os empreendimentos devem realizar uma atividade econômica, conforme a Secretaria Nacional de Economia Solidária (SENAES). Os outros três princípios básicos da Economia Solidária fazem com que ela se apresente, também,

\footnotetext{
4 Não descartamos a hipótese de haver outros segmentos na Economia Solidária, ou mesmo, a possibilidade de outras classificações para eles. Porém, neste trabalho, optamos por apresentar os segmentos conforme estão propostos.
} 
Artigo | Os desafios para a economia solidáría em uma sociedade do consumo (NEVES, Ednalva Felix das; MEZZACAPPA, Gabriela Gonzales; PALMIERI JÚNIOR, Valter)

como uma alternativa ao capitalismo; são eles a solidariedade, a cooperação e a autogestão (SENAES, 2006). Para alguns pensadores da Economia Solidária (como Singer, Gaiger e outros), estes quatro princípios básicos, somados à propriedade e gestão coletiva dos meios de produção; à organização e divisão do trabalho de forma coletiva; à divisão equitativa dos resultados do processo produtivo; e à produção de bens para satisfazer as necessidades humanas (e não para acumular capital) são os pontos fortes da Economia Solidária, que fazem com que ela se apresente como uma alternativa, também, ao sistema capitalista de produção, e sinaliza a construção de uma outra sociedade (SINGER, 2000; 2002; GAIGER, 2003).

Contudo, se sob uma perspectiva teórico-conceitual, a Economia Solidária se apresenta como uma proposta importante rumo à construção de uma alternativa ao capitalismo, por outro lado, a realidade empírica tem sinalizado que os Empreendimentos de Economia Solidária (EES) têm enfrentado vários obstáculos para sobreviver, e o próprio movimento da Economia Solidária tem enfrentado grandes contradições, uma vez que estes empreendimentos estão inseridos no sistema capitalista de produção (NEVES, 2014).

Sobre esta questão é possível destacar dois movimentos: em primeiro lugar, é importante destacar que os EES têm apresentando uma frágil inserção no mercado, o que faz com que tenham grandes dificuldades para gerar a quantidade de postos de trabalho e renda necessários para promover a inclusão social e melhoria nas condições de vida dos trabalhadores da Economia Solidária, conforme era esperado. Em segundo lugar, a Economia Solidária enfrenta uma contradição decorrente do fato de que o fortalecimento dos EES, de maneira imediata, pode prescindir de sua inserção no mercado capitalista, o que, por sua vez, implica na adesão à lógica da economia capitalista. E, uma vez que se insiram no mercado, os EES necessitam pautar suas ações nas "regras" do mercado, baseadas na competição, centralização da gestão, busca pela geração de lucros, etc. - aspectos estes, contraditórios aos princípios da Economia Solidária (NEVES, 2016). Aliás, sobre este segundo aspecto, pode-se destacar que a própria oposição da Economia Solidária à lógica mercadológica capitalista, torna a inserção dos EES no mercado uma séria contradição.

Contudo, vale destacar que mesmo estando (ainda) inserida numa lógica mercadológica e vivendo uma contradição, a Economia Solidária tem aponta do para um 
Artigo | Os desafios para a economia solidáría em uma sociedade do consumo (NEVES, Ednalva Felix das; MEZZACAPPA, Gabriela Gonzales; PALMIERI JÚNIOR, Valter)

horizonte de rompimento com este modelo, buscando criar alternativas para um outro modelo de sociedade. É neste sentido que surgem as propostas para um novo modelo de consumo, consciente e solidário. Entretanto, antes de tratarmos dele, faz-se necessário entender a crítica ao papel do consumo na sociedade capitalista, em que a satisfação de necessidades passa a ter papel secundário - uma vez que o consumo ganha um novo significado: o de atender também ao desejo de status e de criação de diferenciações entre as pessoas. Esta discussão é de suma importância para entender de que maneira a Economia Solidária está formulando sua proposta para a construção de um modelo alternativo ao capitalista, e mesmo, para, posteriormente, entender os limites e potencialidades desta proposta, uma vez estando inserida neste mesmo modelo.

\section{Sistema capitalista: produção e distribuição de bens e a sociedade de consumo}

De acordo com a teoria econômica neoclássica, é por meio das empresas capitalistas que a produção e comercialização de bens garantem o consumo destes bens pelas famílias. Trata-se de uma relação que coloca produtores (empresas) e consumidores (famílias) em situações opostas - situação de competição para (cada um deles) tirar melhor proveito da situação, a partir do que deseja/busca: as empresas buscam maximizar lucro; enquanto que as famílias buscam maximizar suas satisfações. Ver o Quadro 1, a seguir: 


\section{Quadro 1: Modelo de funcionamento da economia capitalista neoclássica}

\begin{tabular}{|l|l|}
\hline \multicolumn{1}{|c|}{$\begin{array}{c}\text { O papel da empresa: produção e } \\
\text { comercialização de bens }\end{array}$} & $\begin{array}{l}\text { O papel do consumidor/famílias: a aquisição dos } \\
\text { bens produzidos pela empresa }\end{array}$ \\
\hline $\begin{array}{l}\text { A produção e comercialização de bens se } \\
\text { dá por meio de unidades produtivas } \\
\text { (empresas), em sua maioria, privadas, } \\
\text { que produzem e vendem estes bens às } \\
\text { pessoas/famílias }{ }^{5} \text {. }\end{array}$ & $\begin{array}{l}\text { O consumo de bens pelas pessoas/famílias é } \\
\text { garantido pela aquisição/compra dos mesmos, } \\
\text { junto às empresas privadas, produtoras destes } \\
\text { bens. }\end{array}$ \\
\hline $\begin{array}{l}\text { O maior motivador da produção e } \\
\text { comercialização de bens é o lucro das } \\
\text { empresas produtoras. }\end{array}$ & $\begin{array}{l}\text { O maior motivador da aquisição de bens pelas } \\
\text { pessoas/famílias é satisfazer suas necessidades } \\
\text { humanas e sociais (de alimentação, vestuários, } \\
\text { habitação, transporte, serviços de saúde e } \\
\text { outros), e assim, garantir sua sobrevivência. }\end{array}$ \\
\hline $\begin{array}{l}\text { O foco da produção e comercialização é } \\
\text { o consumidor, mas tendo como objetivo } \\
\text { maior, garantir a realização do lucro }{ }^{6} .\end{array}$ & $\begin{array}{l}\text { O provedor dos bens para satisfazer as } \\
\text { necessidades dos consumidores são as empresas } \\
\text { privadas, responsáveis pela produção e e } \\
\text { comercialização dos bens. }\end{array}$ \\
\hline $\begin{array}{l}\text { A operação exige a troca de bens por } \\
\text { dinheiro-empresa oferece o bem e em } \\
\text { troca, recebe o dinheiro do consumidor. }\end{array}$ & $\begin{array}{l}\text { A garantia da aquisição só ocorre por meio da } \\
\text { troca de dinheiro por bens - para adquirir o bem, } \\
\text { o consumidor oferece o dinheiro (e para conseguir } \\
\text { odinheiro, oferta seus recursos produtivos -força } \\
\text { de trabalho, capacidade empresarial, etc.) }\end{array}$ \\
\hline
\end{tabular}

Fonte: elaboração própria, com base em Manuais de Economia, como Passos e Nogami (2000).

Ainda de acordo com a teoria econômica (neoclássica) o consumo, no sistema capitalista de produção, só é garantido uma vez que os consumidores consigam adquirir seus bens por meio da compra dos mesmos, no mercado. Por outro lado, é possível perceber que a compra dos bens pelos consumidores só é possível, caso as empresas produzam e comercializem estes bens. Ou seja, trata-se de uma via de mão dupla, envolvendo dois atores (empresas e consumidores), e mediada pelo "mercado". Enquanto o primeiro (empresa) deve garantir a produção e comercialização dos bens ${ }^{7}$,

\footnotetext{
5 A realidade empírica conta com a existência de empresas públicas, cooperativas tradicionais (e, ultimamente, até de EES) no processo produtivo e mesmo de comercialização. Contudo, este quadro representa uma simplificação, a partir da teoria neoclássica.

${ }^{6}$ Com relação a questão da comercialização de bens, entendemos que ela não ocorre apenas para consumidores finais, isto é, existem empresas que produzem bens para outras empresas, isto é, bens que farão parte do processo produtivo de outras empresas (máquinas e equipamentos, matérias-primas, etc.). ${ }^{7}$ Deve-se destacar que o processo de produção e comercialização de bens nem sempre se dá pela mes ma empresa, ao contrário, na maioria dos casos, a empresa produtora comercializa para lojas e comércios
} 
Artigo | Os desafios para a economia solidáría em uma sociedade do consumo (NEVES, Ednalva Felix das; MEZZACAPPA, Gabriela Gonzales; PALMIERI JÚNIOR, Valter)

o segundo (consumidor) deve garantir a compra e o pagamento dos mesmos. A comercialização dos bens garante, portanto, o seu consumo, na sociedade capitalista, ao mesmo tempo em que garante o lucro das empresas (PASSOS e NOGAMI, 2000).

É importante destacar que as necessidades, que motivam o consumo, vão além simples satisfação de necessidades de sobrevivência. Ou seja, o consumo de bens também é influenciado por desejos que, muitas vezes, são motivados por outros fatores, que não apenas aqueles que garantem a sobrevivência, conforme discorreremos a respeito a seguir - esta discussão terá como base, especialmente, as contribuições do sociólogo Jean Baudrillard, que tem sido um dos principais pensadores sobre a questão da sociedade de consumo.

Baudrillard (2006) afirma que a sociedade de consumo é a etapa contemporânea do capitalismo, onde a lógica do mercado incorporou a lógica social do consumo, que é da diferenciação social, uma vez que o processo de identificação e criação de personalidade (ou identidade) requer uma diferenciação entre os membros da sociedade - tal processo de diferenciação, que vê o consumo como critério de identificação, sempre existiu em diferentes sociedades, mas o que é particular da sociedade de consumo é que o mercado define essas diferenças.

Já em 1899, no contexto da segunda revolução industrial, Veblen (1983) afirmava a importância do consumo como critério de prestígio social. Porém, para Baudrillard (2006) a "sociedade de consumo" nasceu no chamado "anos dourados", pois foram as transformações dos anos 1950/60 que permitiram uma efetiva massificação de várias mercadorias produzidas e com isso a inclusão de toda a sociedade nesse sistema de manipulação dos significados do consumo. A massificação gerou, ao mesmo tempo, a maior diferenciação, que é justificada não pelo valor de uso desses objetos, mas pelos significantes sociais dos diferentes objetos.

Com isso, o consumo passou a ter uma função fundamental de instituir, ou preservar, uma ordem hierárquica de valores, que o caracteriza como algo que ultrapassa a fronteira do econômico. Dessa forma, as transformações do capitalismo no segundo pós-guerra modificaram o modo de vida, fazendo com que o consumo de

em geral que, por sua vez, comercializam para o consumidor final. No entanto, em ambos os casos, o objetivo é o lucro que a operação gera. Sendo assim, optamos por simplificar o processo. 
Artigo | Os desafios para a economia solidáría em uma sociedade do consumo (NEVES, Ednalva Felix das; MEZZACAPPA, Gabriela Gonzales; PALMIERI JÚNIOR, Valter)

mercadorias ganhasse novos significados mais claramente voltados ao social (ou mais especificamente, relacionado à diferenciação das pessoas, à status e posição social).

Assim, a constituição da sociedade de consumo em massas se deu nos "anos dourados" do capitalismo, no pós-segunda guerra, momento que, segundo Hobsbawm (1995, p. 224), foi marcado pela "mais impressionante, rápida e profunda revolução nos assuntos humanos de que a história tem registro". A massificação do consumo foi possibilitada por uma série de fatores históricos nas esferas econômica (políticas keynesianas de geração de emprego e renda e aplicação da tecnologia para produção em massa), política (guerra fria, já que esse novo paradigma geopolítico tornou fundamental uma série de mudanças na participação da sociedade na democracia), social (construção do welfare states) e cultural (urbanização, nova configuração familiar, cultura jovem, meios de comunicação de massa), etc.

É importante enfatizar que a constituição da sociedade de consumo foi possível historicamente não apenas pelas transformações na produção em massa (fordismo), mas também por: maior segurança em relação ao futuro propiciado com a construção do Estado de Bem Estar Social; políticas econômicas e sociais que geravam maior nível de empregos e salários; diminuição do custo dos alimentos, devido ao aumento da produtividade nos campos - esses dois últimos fatores contribuíram para que uma maior parcela dos salários dos trabalhadores pudesse ser utilizada para consumir um leque maior de mercadorias novas; outro fator importante foi o maior acesso ao crédito para o consumidor e mudanças nos meios de comunicação de massa (TV, rádio e publicidade).

As inúmeras transformações deste período impactaram profundamente 0 capitalismo e a sociedade, fazendo surgir, desse modo, o que Guy Debord (1997, p. 30) chamou de imensa "acumulação de espetáculos" ou, conforme o autor, "o momento em que a mercadoria ocupou totalmente a vida social" e, com isso, "não apenas a relação com a mercadoria é visível, mas não se consegue ver nada além dela: O mundo que se vê é o seu mundo".

Baudrillard (2006) foi além em sua análise, ao destacar que a sociedade de consumo não deve ser considerada apenas pela intensificação da importância dada à mercadoria (que passou a ocupar todas as esferas da vida social): a lógica social e cultural do consumo se integrou ao imperativo da acumulação de capital, que passou a 
Artigo | Os desafios para a economia solidáría em uma sociedade do consumo (NEVES, Ednalva Felix das; MEZZACAPPA, Gabriela Gonzales; PALMIERI JÚNIOR, Valter)

ter importância na sociedade de consumo, e com isso, tudo se transforma em modelos consumíveis (signos).

A produção de mercadorias e necessidades de consumo não possuem o mesmo ritmo, já que a primeira é função do processo de acumulação de riqueza e a segunda é função da lógica da diferenciação social, que ocorre em uma estrutura social hierarquizada por classes sociais. Esse descompasso entre o ritmo de produção e consumo de mercadorias foi melhor percebido nos "anos dourados" e é por esta razão que o processo de criação de novas necessidades de consumo se tornou uma força produtiva, buscando conciliar estes dois aspectos (produção e consumo). E is to se deu porque, para acumular valor, o capital necessitava não a penas de profundas mudanças no sistema produtivo, mas também, penetrar na esfera cultural da sociedade, engendrando dessa forma, uma maneira de fazer com que o consumo se adequasse ao ritmo que garantisse a continuidade do processo de acumulação de capital.

Desse modo, a contradição entre a capacidade ilimitada de produção e limitada de consumo pode ser atenuada, isto é, por meio da ampliação do consumo, motivada pela criação infindável, e sempre renovada, de necessidades. Este fenômeno evidenciou que o limite do capital é apenas o próprio capital, uma vez que a continuidade da acumulação foi assegurada por esta transformação no "mundo do consumo" e do sistema de necessidades humanas.

Baudrillard (1995) utiliza categorias da semiologia para compreender a lógica do consumo na sociedade contemporânea, já que o objeto é um veículo material, que contém uma linguagem de significações e hierarquizações sociais, além de ter uma funcionalidade prática (valor de uso) e ser um intercâmbio econômico (valor de troca). É por meio da linguagem de significações do objeto que se compreende os mecanismos de criação de necessidades no capitalismo contemporâneo, já que as necessidades não se referem fundamentalmente à funcionalidade prática, mas principalmente à lógica social do consumo, que é a da diferenciação social.

Assim, "consumir" está relacionado, também, à intenção do indivíduo em aderir a determinados valores, uma escolha que, na visão de Baudrillard, é eminentemente inconsciente, uma vez que as pessoas apenas aceitam um estilo de vida determina do pela sociedade na qual estão inseridas. Dessa forma, é possível afirmar que, para que este sistema funcione, existem mecanismos próprios da produção de bens que são 
Artigo | Os desafios para a economia solidáría em uma sociedade do consumo (NEVES, Ednalva Felix das; MEZZACAPPA, Gabriela Gonzales; PALMIERI JÚNIOR, Valter)

planejados para que haja um sistema de descartabilidade das mercadorias, a fim de garantir que o consumo tenha uma dimensão ilimitada na sociedade.

A linguagem do objeto é determinada pelos modelos, que são produzidos industrialmente. A criação de necessidades ocorre por intermédio da dinâmica social do modelo, que é fundamental para a reprodução do capital - pois a lógica da moda permite um maior descarte dos objetos e incita os desejos de consumo. Os déficits técnicos (referentes à mudança tecnológica), estéticos (onde a lógica da moda modifica o valor estético da sociedade) e de atualidade (em que apenas por ser "atual", a mercadoria já é considerada mais moderna) afastam a série (objeto real) do modelo (padrão ideal), estratificando e hierarquizando a sociedade e contribuindo para uma maior descartabilidade dos objetos de consumo.

Esta lógica cria uma cultura de permanente "renovação" das mercadorias consumidas, fazendo com que aqueles que não participam da "atualidade" da mercadoria sejam excluídos de uma certa sociabilidade. É essa a lógica da moda no capitalismo, pois apesar de incluir toda a população nesse sistema simbólico, cria um modo de (re)conhecimento onde poucos podem participar (materialmente e culturalmente). Este fenômeno é responsável por criar novas segregações sociais - que é o que alimenta a própria lógica deste sistema.

Portanto, a esfera cultural na sociedade contemporânea é, cada vez mais, marcada por este processo, em que a mercantilização e o consumo de objetos tornamse a principal forma de expressão dos valores sociais - o consumo de um carro, roupas, acessórios, atividade física, alimentos, hábitos culturais e artísticos e etc., demonstram status e prestígio social, pois a personalização (ou despersonalização) ocorre através do consumo desses objetos.

A personalização acontece não em relação à função "essencial" do objeto consumido, mas do supérfluo. Apenas o fato de ter um determinado bem/objeto não é suficiente, é preciso ter aquele objeto que causa diferenciação - por exemplo, ter um carro, uma máquina de lavar, um notebook ou celular não é suficiente para distinguir as pessoas, é necessário ter uma determinada marca ou modelo (uma "Mercedes", uma Brastemp; a última geração notebook ou celular, etc.). A diferenciação social ocorre por meio da capacidade individual de manipulação dos significantes do objeto. 
Artigo | Os desafios para a economia solidáría em uma sociedade do consumo (NEVES, Ednalva Felix das; MEZZACAPPA, Gabriela Gonzales; PALMIERI JÚNIOR, Valter)

A diferenciação entre os indivíduos, classes sociais e grupos, não ocorre apenas através da posse e uso dos objetos, mas também da representação social desses objetos. A lógica da diferenciação para Baudrillard não se refere à necessida de de se diferenciar que os indivíduos possuem entre si, pois os indivíduos se diferenciam ao compartilhar os signos de um determinado grupo social. Quer dizer, cada grupo social partilha de um mesmo código e signos. Portanto, consumir é participar de um sistema de trocas socializadas de signos. É a troca das diferenças codificadas, e não das reais, que constrói o grupo.

A abundância de mercadorias possibilitou a falsa liberdade de escolhas. Na verdade, escolhas em relação a detalhes supérfluos dos objetos são os aspectos que passaram a identificar os indivíduos - a cor do carro, a marca da geladeira, ou matériaprima da jaqueta (jeans, couro ou sarja). São esses tipos de escolhas que permitem dizer sobre a posição social e características pessoais dos indivíduos.

Conforme já mencionamos, essas escolhas estão relacionadas com a lógica produtivista do capitalismo, que cria um processo infindável de produção de necessidades utilizando-se da ideia de modelos (padrões ideais) que são transferidos do topo para a base das hierarquias sociais. Quanto maior o poder aquisitivo e habilidade cultural de manipulação dos signos, mais competitivo é o indivíduo na sociedade da acirrada busca pela diferenciação social e, consequentemente, pela personalização.

Neste contexto, a cidadania, que foi conquistada por meio de um longo processo de lutas por maiores direitos individuais, políticos e sociais, contribuiu para que a sociedade contemporânea se tornasse dependente de outro direito: o do consumidor. Além disso, quem não possui as mercadorias da moda torna-se um "excluído social", perdendo o status de cidadão conquistado pelo processo civilizatório, já que determinados objetos tornam essenciais para a sociabilidade moderna.

É importante destacar que a "abundância" e a democratização do hedonismo, através da massificação do consumo, não possui a capacidade de oferecer maior liberdade e igualdade aos indivíduos. Pelo contrário, a democratização existe apenas no âmbito dos desejos de consumo, já que a elevada desigualdade em relação ao poder de compra não permite que esses desejos se tornem realidade para uma boa parte da população. Nesse sentido, a desigualdade no plano simbólico apenas se eleva na sociedade de consumo. 
Artigo | Os desafios para a economia solidáría em uma sociedade do consumo (NEVES, Ednalva Felix das; MEZZACAPPA, Gabriela Gonzales; PALMIERI JÚNIOR, Valter)

O problema se torna ainda mais grave se pensarmos nas consequências do desenvolvimento da sociedade de consumo nos países periféricos, que consomem, em sua maioria, objetos produzidos pelos países avançados - sendo que os países periféricos não possuem capacidade autônoma de financiamento e inovação, além do fato de possuírem maior nível de desigualdade de renda. Assim, além deste estilo de vida contribuir para a polarização social, neste caso, o consumo promove crescimento e desenvolvimento nos países desenvolvidos, produtores destas mercadorias, e não nos países periféricos. Em virtude disso, pode-se afirmar que estes países possuem um incentivo a mais para promover uma ruptura com este padrão de sociedade de consumo. Neste sentido, seria importante refletir sobre: como sair do subdesenvolvimento quando "desenvolvimento" na maior parte dos países avançados significa intensificara lógica da sociedade de consumo? Afinal, o modelo de crescimento econômico atualmente depende, de modo global, do consumo individual, massivo, descartável e supérfluo. Como gerar renda e emprego em um país, sem depender do direcionamento do investimento para elevar a capacidade produtiva de um consumo individual desenfreado? Como negar em uma democracia capitalista a democratização dos bens produzidos pelo capitalismo? Em suma, para além da defesa de um modelo de sociedade não polarizado e excludente, os países periféricos devem repudiar este modelo por torná-los dependentes e empobrecidos.

\section{Consumo Consciente e Solidário: a proposta alternativa da Economia Solidária}

O enfrentamento dos problemas de uma sociedade só poderá ser bem-sucedido quando se (re)conhece quais são estes problemas, e quando os submetemos à uma análise crítica. Dessa forma, este trabalho buscou contribuir para a compreensão da sociedade capitalista contemporânea, principalmente em relação à questão do consumo, para então, refletir sobre possíveis formas de enfrentamento das questões aqui levantadas, em especial, com as reflexões acerca do papel da Economia Solidária, enquanto potencial de transformar a sociedade.

Neste contexto, vale destacar que, até mesmo a crítica ao "insustentável" modo de consumir pode tornar-se um elemento capaz de diferenciar os grupos sociais. Portanto, reconhecer este problema não, necessariamente, acarreta uma crise ao 
Artigo | Os desafios para a economia solidáría em uma sociedade do consumo (NEVES, Ednalva Felix das; MEZZACAPPA, Gabriela Gonzales; PALMIERI JÚNIOR, Valter)

modelo da sociedade de consumo, pois as críticas podem ser incorporadas por esta lógica e utilizadas em seu favor. Baudrillard (2008, p. 268) já alertava, na década de 1970, que "assim como a sociedade da Idade Média se equilibrava em Deus e no Diabo, assim a nossa baseia no consumo e na sua denúncia". Sendo assim, as críticas e ações individuais podem apenas reforçar o poder da "ideologia do consumo" que se apropria de ideias como "consumo sustentável", "consciente" e "ecologicamente correto", para reproduzi-las pela indústria, que tem o poder de englobar as críticas ao próprio modelo de produção industrial, ressignificando-as em seus próprios objetos. Diante disso, exemplos como os produtos orgânicos, madeira certificada e "comida caseira", etc., são oferecidos pela indústria (capitalista) com um preço adicional, mas também oferecem signos para os "consumidores conscientes", mas sempre se mantendo dentro da lógica da sociedade do consumo.

Diante do que vem sendo exposto até aqui, pode-se afirmar que, não é sem razão que, Portilho (2005) destaca que o consumo é a mola propulsora da sociedade atual, sendo que, inclusive bens imateriais, como a força de trabalho, a cultura e as relações humanas são "comercializadas" e atendem à mesma lógica de funcionamento do capitalismo de maneira geral (competição, individualismo, descartabilidade) ${ }^{8}$. Assim, alguns pensadores já vêm destacando que o papel do consumo vai além do econômico:

$O$ ato de consumo não é apenas econômico, mas também ético e político", sendo assim, ele representa "um exercício de poder pelo qual efetivamente se pode tanto apoiar a exploração de seres humanos, a destruição progressiva do planeta, a concentração de riquezas e a exclusão social, quanto se contrapor a esse modo lesivo de produção" (MANCE, 2009, p. 74).

E neste contexto, algumas propostas apontam para a necessidade de se construir práticas alternativas na linha do consumo responsável, consciente e solidário. $\mathrm{O}$ consumo responsável pode ser entendido como "um conjunto de hábitos e práticas que fomentam um modelo de desenvolvimento comprometido com a redução da desigualdade social e dos impactos ambientais" (PORTAL DO CONSUMO RESPONSÁVEL, 2018) ${ }^{9}$.

\footnotetext{
8 Outro autor que corrobora esse ponto de vista é Bauman (2008).

${ }^{9}$ Consultar em: http://consumoresponsavel.org.br/carta-politica/
} 
Artigo | Os desafios para a economia solidária em uma sociedade do consumo (NEVES, Ednalva Felix das; MEZZACAPPA, Gabriela Gonzales; PALMIERI JÚNIOR, Valter)

Tendo como pano de fundo a crítica ao modelo da sociedade do consumo e de que "esse modelo de desenvolvimento é insustentável e que a melhor maneira de transformá-lo é por meio da prática de um outro tipo de consumo, que estimule outras práticas de produção, serviços, colaboração etc.", a proposta de consumo responsável propõe:

[...] um conjunto de hábitos e práticas que fomentam um modelo de desenvolvimento comprometido com a redução da desigualdade social e dos impactos ambientais. Busca melhorar a produção, distribuição e aquisição de produtos e serviços, incentivando as práticas colaborativas. É a vivência de atitudes éticas para a construção conjunta de um novo panorama social, econômico e ambiental por meio da [agroecologia, segurança alimentar e nutricional/soberania alimentar, economia solidária e comércio justo e solidário e agricultura camponesa/familiar] (PORTAL DO CONSUMO RESPONSÁVEL, 2018; grifos nossos).

É neste contexto que a Economia Solidária vem construindo uma proposta diferente de consumo, baseada na ideia de "Consumo Consciente e Solidário". Segundo, o Instituto Akatu"10 (2011) "consumir com consciência é consumir diferente, tendo no consumo um instrumento de bem-estar e não um fim em si mesmo". Rumo a um estilo de consumo consciente, a Akatu propõe, dentre outras coisas, o planejamento das ações de consumo, evitando as compras por impulsividade; a reutilização de produtos e embalagens; separação e reciclagem do lixo; o consumo apenas de itens necessários; a reflexão sobre os valores pessoais e a avaliação dos impactos do consumo; etc.

O consumo solidário, por exemplo, busca, não apenas viabilizar o escoamento da produção de bens pelos EES, como também, promover, de maneira empírica, "a ampliação das liberdades públicas e privadas, a desconcentração da riqueza e o desenvolvimento ecológica e socialmente sustentável" (MANCE, 2009, p. 74). Desta maneira, uma importante ação, no sentido de promover uma mudança de sociedade pode se dar, por exemplo, por meio do consumo de produtos da Economia Solidária:

Quando uma pessoa seleciona e consome produtos e serviços da economia solidária, o valor econômico por ela despendido para tanto realimenta a produção solidária em prol do bem-viver de todos os que integram as redes solidárias de produtores e consumidores e, igualmente, fomenta a manutenção do equilíbrio dinâmico dos ecossistemas (MANCE, 2009, p. 74).

\footnotetext{
${ }^{10}$ Consultar em: https://www.akatu.org.br/noticia/conheca-os-12-principios-do-consumo-consciente/
} 
Artigo | Os desafios para a economia solidária em uma sociedade do consumo (NEVES, Ednalva Felix das; MEZZACAPPA, Gabriela Gonzales; PALMIERI JÚNIOR, Valter)

A justificativa da importância de se consumir produtos da Economia Solidária, enquanto um modelo de consumo consciente e solidário se dá por alguns fatores: primeiro porque, assim como a crítica tecida à sociedade do consumo, a Economia Solidária tece uma crítica ao modelo capitalista, por perceber nele um modelo que produz danos à sociedade. Em segundo lugar, a proposta da Economia Solidária se pauta em alternativas sustentáveis de desenvolvimento econômico e social, em que o ser humano esteja no centro das preocupações (e não seja apenas usado como arma para promover o crescimento econômico das empresas e países). E por fim, ainda no que se refere à questão da sustentabilidade, ambas as propostas defendem e constroem alternativas que preservem o meio ambiente.

Porém, é importante que o ato de consumir produtos da Economia Solidária não ocorra simplesmente pela influência de modismo (ou do "consumo alienado" que, em geral, é "praticado por influência das semioses publicitárias"). Istoé, o consumo de bens da Economia Solidária não deve ocorrer da mesma maneira como vem ocorrendo o fomento às, assim chamadas, economias sustentáveis - nomenclatura que carrega simplesmente uma ideologia de fomento ao próprio consumismo. Ao contrário disso, ele deve ser fruto de uma tomada de consciência da necessidade de se modificar práticas que são maléficas para a sociedade, voltadas para a construção de uma sociedade sustentável, mais justa e igualitária. Neste sentido,

O consumo solidário é aquele praticado em função não apenas do bem-viver pessoal, mas também do bem-viver coletivo, em favor dos trabalhadores que produzem, distribuem e comercializam os bens e serviços consumidos e, igualmente, em prol da manutenção do equilíbrio dinâmico dos ecossistemas. Trata-se, pois, do consumo em que se dá preferência aos produtos e serviços da economia solidária em relação aos produtos de empresas que exploram os trabalhadores e degradam os ecossistemas. $O$ consumo solidário é igualmente praticado com vistas a contribuir-se à geração e manutenção de postos de trabalho sob estratégias de desenvolvimento territorial sustentável, para se preservar o equilíbrio dos ecossistemas e melhorar o padrão de consumo dos participantes de redes colaborativas solidárias (MANCE, 2009, p. 75).

Desta maneira, o consumo solidário estaria contribuindo para a "construção de sociedades mais justas e sustentáveis", enquanto combateria exclusão social e a degradação do meio ambiente (MANCE, 2009, p. 75). 
Artigo | Os desafios para a economia solidáría em uma sociedade do consumo (NEVES, Ednalva Felix das; MEZZACAPPA, Gabriela Gonzales; PALMIERI JÚNIOR, Valter)

Outros autores também apontam a importância de hábitos de consumo diferentes dos vigentes na sociedade do consumo para a minimizar os impactos socioambientais do capitalismo. Pode-se citar o levantamento realizado por Mezzacappa (2013), que pontua conceitos afins ao do consumo ético, solidário e responsável, quais sejam, o consumo crítico (MANCE, 2002), o "consumerismo" (HENRIQUES, 2008) e o consumo sustentável (FURRIELA, 2001). Alguns destes conceitos abarcam questões socioambientais relevantes, porém apenas o consumo solidário faz referência ao fortalecimento das iniciativas da Economia Solidária. Esta ideia tem sido debatida pelos estudiosos do tema como uma forma de possibilitar a construção de alternativas para fortalecer o consumo na Economia Solidária, como uma proposta que envolve não apenas os produtores, mas também, os consumidores nos processos relacionados à transformação da sociedade. O envolvimento dos consumidores nas questões pertinentes à transformação da sociedade parece um importante passo, uma vez que viabiliza a comercialização dos produtos da Economia Solidária, o que garante a concretização das rendas geradas na lógica da produção.

É importante que se destaque que as escolhas feitas pelos consumidores têm grande influência sobre a sociedade, por isso elas precisam se pautar: na "redução do consumo de itens inúteis, descartáveis, que despendem recursos não-renováveis, etc."; na "reutilização dos bens, abandonando modismos, adquirindo produtos usados, etc."; na "reparação dos bens que se danificam, aumentando sua vida útil"; e na "reciclagem de tudo que seja possível, reduzindo o descarte e a emissão de resíduos" (MANCE, 2009, p. 76). A proposta prevê ainda, outras práticas que colaboram para a construção deste outro modelo de sociedade, como:

[...] não desperdiçar energia (petról eo e outros recursos) e privilegiar o uso da energia renovável; agir defensivamente nos supermercados (uma vez que a música ambiental, a exposição dos objetos, as entregas em domicílio, a facilitação de pagamento, o incentivo ao endividamento, as publicidades e outros elementos visam incitar ao consumo de bens que, a rigor, seriam dispensáveis); encorajar os serviços coletivos - em particular, o uso do transporte público - ou a utilização coletiva de equipamentos tais como lavadoras, computadores, etc.; por fim, superar o medo da sobriedade, isto é, perceber que é possível viver confortavelmente dispondo de menos objetos e utensílios os quais, muitas vezes, nada acrescentam significativamenteàs mediações necessárias ao bem-viver (MANCE, 2009, p. 76). 
Artigo | Os desafios para a economia solidáría em uma sociedade do consumo (NEVES, Ednalva Felix das; MEZZACAPPA, Gabriela Gonzales; PALMIERI JÚNIOR, Valter)

Desta maneira, estaríamos criando as bases para uma nova consciência a res peito do consumo - o que seria de extrema relevância para uma outra sociedade. Esta nova forma de pensar e agir seria baseada em um consumidor consciente do seu papel e da importância da sua ação na transformação da sociedade. É importante destacar que, se por um lado, os estudiosos da Economia Solidária têm destacado seu importante papel na transformação da sociedade, por meio das mudanças promovidas no setor produtivo - em especial, por contestar a propriedade privada, a geração de lucro e a exploração do trabalho - por outro, é importante que se evidencie que a esfera (ou lógica) produtiva depende da esfera (ou lógica) de comercialização para sobreviver. Neste sentido, o fomento ao consumo dos produtos da Economia Solidária ganha papel de extrema relevância, uma vez que os consumidores buscariam superar a sociedade de consumo, ao mesmo tempo em que constroem uma nova consciência capaz de assegurar a construção de uma sociedade mais justa, igualitária e sustentável.

E, apesar das contradições inerentes à inserção das iniciativas econômicas solidárias em uma sociedade capitalista - o que, inevitavelmente, inclui o papel do consumo (NEVES, 2016) - diversas alternativas vêm sendo desenvolvidas para fomentar práticas de um consumo politicamente orientado para o fortalecimento da Economia Solidária. Dentre as possibilidades de articulação nesse sentido estão os coletivos de consumidores. Além de ações facilitadoras e promotoras de hábitos de consumo ético, solidário e responsável, esses coletivos costumam realizar atividades educativas e formativas direcionadas a consumidores, de forma a sensibilizá-los para além dos modismos, mas para tornar seus hábitos de consumo verdadeiramente orientados como atos políticos - vale destacar que, segundo o Instituto Kairós (2010), havia, em 2010, dezessete grupos de consumo responsável no país ${ }^{11}$. Mezzacappa (2013) cita, ainda, alguns exemplos no interior do estado de São Paulo, tais como o ConsumoSol, o Instituto Terra Mater ${ }^{12}$, a Rede Guandu de Consumo Solidário ${ }^{13}$, e o coletivo Trocas Verdes $^{14}$.

Os coletivos de consumidores, ou grupos de consumo responsável, são em geral organizações da sociedade civil informais ou de caráter associativo. Dentre suas ações

11 Embora atualmente esse número seja possivelmente maior.

12 Maiores informações em: $\underline{\mathrm{HTTP}: / / \text { www.terramater.org.br }}$

13 Maiores informações em: $\underline{\text { HTP:://www.terramater.org.br/guandu/?cat=6 }}$

14 Maiores informações em: $\underline{\text { HTP://www.trocasverdes.org }}$ 
Artigo | Os desafios para a economia solidáría em uma sociedade do consumo (NEVES, Ednalva Felix das; MEZZACAPPA, Gabriela Gonzales; PALMIERI JÚNIOR, Valter)

destacam-se compras coletivas de produtos orgânicos e artesanais, promoção do contato direto entre produtor e consumidor em feiras, eventos e outras estratégias de compra direta, fomento de práticas de comercialização justa, com diálogo entre produtores e consumidores e transparência nas relações comerciais, articulação de formas alternativas de acesso a produtos e serviços, como feiras de trocas, bancos de tempo, uso de moeda social, entre outras estratégias de ação (KAIRÓS, 2010).

Por exemplo, no escopo de ações do coletivo ConsumoSol, de São Carlos, no interior de São Paulo, estão incluídos aspectos administrativos (monitoramento de mensagens, fundo, reuniões, boletins informativos - que também têm caráter de favorecimento de práticas de consumo solidário, etc.); de aproximação entre produtor e consumidor (mapeamento de produtores da Economia Solidária, mediação de compras coletivas e divulgação de EES e de pequenos produtores); educativos (estudo para proposição de uma escola de consumo solidário, elaboração de programas de ensino enfocando hábitos e condições específicas dentro da temática, realização de cursos para educadores e de oficinas temáticas, entre outros); de inserção na comunidade (participação no Fórum Municipal de Economia Solidária, atuação junto a EES, aproximação com a Rede de Coletivos de Consumidores); de participação em eventos acadêmicos e da Economia Solidária, de estabelecimento de parcerias com instituições públicas, privadas, consumidores e produtores; de promoção de hábitos de consumo solidário (Cine ConsumoSol - debate de temas relacionados ao consumo a partir de filmes, divulgação de dicas de consumo solidário e consciente, promoção de práticas de consumo solidário entre os membros do grupo); da articulação e execução de projetos (Sacoleco - uso de suportes duráveis para compras, educação para o consumo, entre outros); e outras atividades (filmagem de documentário sobre EES e sobre o ConsumoSol, estudo para a formalização do grupo) (MEZZACAPPA, 2013).

Pode-se citar também, conforme levantamento realizado por Bueno (2010), outras iniciativas autônomas que, se não se caracterizam como coletivos de consumidores, têm entre suas propostas a educação para um consumo consciente, quais sejam os institutos Akatu, Kairós, Alana e o Instituto de Defesa do Consumidor ${ }^{15}$.

15 Bueno (2010) também lista iniciativas governamentais que abordam a temática, embora não necessariamente com um viés condizente com os princípios da Economia Solidária. Essas iniciativas são a Fundação de Proteção e Defesa do Consumidor (PROCON) e o Departamento de Proteção e Defesa do Consumidor (DPDC). 
Artigo | Os desafios para a economia solidáría em uma sociedade do consumo (NEVES, Ednalva Felix das; MEZZACAPPA, Gabriela Gonzales; PALMIERI JÚNIOR, Valter)

Assim, uma diversidade de ações de promoção de práticas de consumo ético, solidário e responsável ou de práticas de consumo afins, seja no sentido de facilitaressas relações, seja no sentido de sensibilizar consumidores em potencial por meio de estratégias informativas e formativas, vêm sendo empreendidas, tanto por iniciativas da esfera pública quanto por iniciativas da sociedade civil organizada. E é importante que se ressalte que estas ações são de suma relevância para a construção de um outro modelo de consumo, mais adequado ao modelo de sociedade sustentável, mais justo e igualitário que se pretende construir (especialmente a Economia Solidária).

\section{Considerações finais}

Este trabalho traz uma reflexão sobre ao modelo insustentável de sociedade, pautado no consumo desenfreado e excludente (sociedade do consumo), que serve apenas para garantir a acumulação de riquezas, mas que gera mazelas ambientais e sociais, e atrelando às discussões e propostas da Economia Solidária, que se propõe a criar uma alternativa de inclusão social, mas também, de construção de uma sociedade sustentável, mais justa e igualitária. Vale lembrar que as discussões sobre estes temas já vêm sendo feita de maneira separadas, ao passo que, neste trabalho, buscou-se construir uma discussão conjunta, capaz de se apresentar como uma possível reflexão que, ao mesmo tempo, resgata as discussões tecidas pelos críticos à sociedade do consumo, para refletir sobre a proposta da Economia Solidária alinhada à proposta do consumo consciente e solidário. Entendemos que apenas a partir deste posicionamento crítico, é possível, de fato, construir uma alternativa capaz de indicar possíveis caminhos para a construção desta alternativa, na linha da Economia Solidária.

Como buscamos mostrar, o sistema capitalista não pode ser visto (e atacado) apenas como um modo de produção - há muito tempo, os problemas gerados pelo capitalismo ultrapassaram este escopo, de maneira que, além de ser um poderoso modo de produção, ele se consolidou também, como um modo de vida, como se criasse teias invisíveis, capazes de capturar a todos que estão a sua volta. Esta percepção nos leva a crer que o combate às práticas abusivas do capitalismo deve ser mais que o combate ao modo de produção capitalista, de modo a tornar-se o combate ao próprio modo de vida capitalista, que engendra a produção de bens, mas também, à circulação dos mesmos, 
Artigo | Os desafios para a economia solidáría em uma sociedade do consumo (NEVES, Ednalva Felix das; MEZZACAPPA, Gabriela Gonzales; PALMIERI JÚNIOR, Valter)

em que se situam a comercialização e o consumo. Sendo assim, não teria sentido que a construção de uma alternativa de inclusão social e de construção de outra sociedade, fosse pautada numa lógica da sociedade do consumo.

É importante destacar que, embora o surgimento da Economia Solidária tenha estado relacionado à necessidade de geração de trabalho e renda e de promoção da oportunidade de inclusão social, no atual estágio da Economia Solidária, que ela se apresenta ao desafio de, também, contribuir para a construção de uma outra sociedade, ela não pode estar relacionada apenas à geração de trabalho e renda. Isto é, a transformação da sociedade exige práticas e princípios que vaiam além deste papel, que incluam condições de trocas, de criação de moedas, e mesmo de criação de espaços para se recriar (e/ou retomar) as formas de vida pautadas numa visão de sociedade mais humanizada.

A construção de uma alternativa, pautada nos ideais da Economia Solidária possibilitaria o surgimento de uma sociedade em que não existiria, por um lado, excluídos da capacidade de consumir (pessoas que passam fome, frio, sem abrigo ou assistência médica e acesso à educação); e por outro, pessoas escravas de um modelo de consumo que gera degradação do meio ambiente (para fabricação de bens) e de geração de resíduos (da obsolescência programada) e a escravização das pessoas a este modelo (uma vez que as pessoas comumente aumentam seu tempo de trabalho, a fim de poder consumir mais e mais bens).

Uma outra questão importante é de "como" realizar a mudança necessária na sociedade, a fim de construir uma nova cultura, adequada aos princípios desta nova sociedade que se almeja criar. É comum a tentativa de se promover mudanças individuais, em que as pessoas são convidadas a mudarem suas práticas diárias de consumo, como forma de promover uma mudança na sociedade. No entanto, é preciso lembrar que a própria lógica consumista do sistema capitalista cria uma espécie de teia que convence, e até mesmo aprisiona, as pessoas nesta lógica - isso não quer dizer que as atitudes individuais não possam ocorrer, ou mesmo que elas não tenham importância, mas sim, mostrar a dificuldade das mudanças individuais, numa sociedade pautada por uma forma de vida em que o consumo é, muitas vezes, um forte fator de inclusão social. Um bom exemplo disso, são os apelos da mídia (as propagandas e o marketing) feitos em torno de certos produtos, a fim de se criar nas pessoas a sensação 
Artigo | Os desafios para a economia solidáría em uma sociedade do consumo (NEVES, Ednalva Felix das; MEZZACAPPA, Gabriela Gonzales; PALMIERI JÚNIOR, Valter)

de necessidade de destes produtos (muitos deles, supérfluos e desnecessários). Além disso, é bastante comum que, a partir dos bens (mercadorias) que as pessoas usam, elas possam ser julgadas, sendo aceitas ou rejeitadas em determinados circuitos sociais (a influência é pior sobre as crianças que são incapazes de distinguir entre o real e o irreal, no que se refere à necessidade).

É importante não ignorar o fato de que as empresas estão atentas às demandas dos consumidores - e mesmo as suas mudanças de gostos e preferências - de maneira que podem mudar suas marcas e signos a fim de atender à uma mudança de consciência. Acontece que, ainda que a mudança de consciência social seja real, o que motiva a mudança das empresas são suas necessidades de maximização de lucros, manutenção e ganho de poder de mercado, melhoria de suas capacidades de concorrência, etc. Assim, uso de selos verdes, ou de símbolos e slogans com apelos à conservação ambiental ou à ações de inclusão social, nem sempre são reais, por parte das empresas - podem representar jogadas de marketing, a fim de iludir (e garantir o consumo de) aquela parcela dos consumidores que aderiram a uma consciência social ou ambiental.

Desta maneira, é evidente que, embora a mudança necessite de pessoas dispostas a entender e se opor a esta lógica perversa, uma real mudança prescinde de uma mudança de consciência que perpasse o âmbito individual e que se dê no plano coletivo. Isto é, é preciso haver formas de educar coletivamente a população, a fim de se criar uma nova forma de lidar com aspectos da vida, que abrangem tanto a lógica da produção, como do consumo de bens - partindo-se das necessidades reais e tendo o "todo" como perspectiva, conforme já mencionado. A luta pela mudança, portanto, deve partir desta perspectiva coletiva, e ao que tudo indica, a Economia Solidária se enquadra (ainda que de maneira tímida) neste modelo de construção coletiva de alternativas para o problema do consumo.

Vale lembrar que o professor Paul Singer (2005, p. 19) destacou que a Economia Solidária "é um ato pedagógico em si mesmo, na medida em que propõe nova prática social e um entendimento novo desta prática". Com isso, Singer sinalizou o importante papel da Economia Solidária enquanto geradora de uma nova consciência. João Bernardo (2005) e Tiriba (2009) também enfatizam o importante papel educativo da Economia Solidária, no sentido de romper com o modelo excludente e explorador do 
Artigo | Os desafios para a economia solidáría em uma sociedade do consumo (NEVES, Ednalva Felix das; MEZZACAPPA, Gabriela Gonzales; PALMIERI JÚNIOR, Valter)

capitalismo. Acrescentamos que ela tem sido capaz também, de sinalizar outras perspectivas para a mudança, como as que envolvem a questão do consumo, já mencionado, do crédito e mesmo das relações interpessoais. Sendo assim, entendemos que ela se apresenta como um modelo pedagógico capaz de fazer aflorar um espírito crítico e analítico, num primeiro momento, e reflexivo e construtivo, em seguida. $E$ assim, promover a educação das pessoas, por meio deste processo contestatório e emancipador, oferecendo, assim, as bases para o rompimento com o velho modelo e a criação de uma nova sociedade. Em suma, a luta da Economia Solidária pode "desencadear o começo de uma tendência" (BERNARDO, 2005) que pode influenciar, também, no consumo.

Por fim, é relevante destacar, também, que há ainda prementes desafios para que o consumo seja realizado como ato político por uma maioria populacional, de forma a acarretar transformações sociais e culturais amplas e concretas. É notório também, que a própria Economia Solidária enfrenta desafios para se concretizar enquanto uma alternativa de sociedade. No entanto, ainda assim, conforme buscamos mostrar, a Economia Solidária tem uma importante contribuição neste processo de mudança e se apresenta como grande potencial para tal.

\section{Bibliografia}

BAUDRILLARD, Jean. Para uma crítica da economia política do signo. São Paulo: Editora Martins Fontes, 1995.

. O sistema dos objetos. São Paulo: Perspectiva, 2006.

. A sociedade de consumo. Lisboa: Edições 70, 2008.

BAUMAN, Zygmunt. Vida para consumo: a transformação das pessoas em mercadoria. Rio de Janeiro: Zahar, 2008.

BERNARDO, João. A autogestão da sociedade prepara-se na autogestão das lutas.

Publicado em Piá Piou!, Novembro de 2005, no 3. Disponível em: http://radiotarrafa.libertar.org/pensamento/a-autogestao-da-sociedade-prepa ra-sena-autogestao-das-lutas/. Acesso em 12/Ago/2018.

BUENO, Igor de Almeida Faria. Análise e programação de contingências favorecedoras de condutas humanas em organizações de trabalho no contexto de 
Artigo | Os desafios para a economia solidáría em uma sociedade do consumo (NEVES, Ednalva Felix das; MEZZACAPPA, Gabriela Gonzales; PALMIERI JÚNIOR, Valter)

economia solidária. Relatório de Estágio. UFSCar: Centro de Educação e Ciências Humanas, Departamento de Psicologia. Mimeo. 2010.

CRUZ. Antônio Carlos Martins. A diferença da igualdade: a dinâmica da economia solidária em quatro cidades do Mercosul. Campinas/SP, 2006. Tese (Doutorado em Economia Aplicada). Universidade Estadual de Campinas.

DEBORD. Guy. A sociedade do espetáculo. Rio de Janeiro: contraponto, 1997.

FURRIELA, Rachel Biderman. Educação para o consumo sustentável. Ciclo de palestras sobre meio ambiente. Programa conheça a educação do CIBEP/InepMEC/COEA. 2001.

GAIGER, Luiz Inácio. A economia solidária diante do modo de produção capitalista. Cadernos do CRH-UFBA. Salvador. V. 39, n. 39, p. 181-211, 2003.

HENRIQUES, Susana. Educação para o consumo. Lisboa; Universidade Aberta, 2008.

HOBSBAWM, Eric. A era dos extremos: o breve séculoXX. São Paulo: Companhia das letras, 1995.

INSTITUTO AKATU PELO CONSUMO CONSCIENTE. Conheça os 12 princípios do consumo consciente. Disponível em: https://www.akatu.org.br/noticia/conheca-os-12principios-do-consumo-consciente/. Acesso em 10/Ago/2018.

INSTITUTO KAIRÓS. Levantamento do Perfil dos Grupos de Consumo no Brasil. "Consumo como intervenção - um olhar sobre as experiências de consumo coletivo no Brasil". Instituto Kairós. 2010. Disponível em http://institutokairos.net/wpcontent/uploads/2012/04/Kairos-grupos-de-consumo-no-brasil.pdf. Acesso em ago/2012.

LAVILLE, Jean-Louis; GAIGER, Luiz Inácio. Economia Solidária. In: CATTANI, Antonio David, et al. Dicionário Internacional da Outra Economia. São Paulo: Almedina, 2009.

MANCE, Euclides André. Consumo Solidário. In: Solidarius. Curitiba. Nov/2002. Disponível em: http://www.solidarius.com.br/mance/biblioteca/consumosolidario.pdf. Acesso em 09/09/2010.

- Consumo Solidário. In: CATTANI, Antônio David, et al. Dicionário Internacional da Outra Economia. São Paulo: Almedina, 2009.

MARX, Karl. O capital: crítica da economia política. São Paulo: Editora Nova Cultural, 1996. 
Artigo | Os desafios para a economia solidáría em uma sociedade do consumo (NEVES, Ednalva Felix das; MEZZACAPPA, Gabriela Gonzales; PALMIERI JÚNIOR, Valter)

MEZZACAPPA, Gabriela Gonzales. Relação Educação Ciência, Tecnologia e Sociedade e elaboração de programas de ensino. São Carlos/SP, 2013. Dissertação (Mestrado em Ciência, Tecnologia e Sociedade). Universidade Federal de São Carlos.

NASCIMENTO, Claudio. (2005) Do “Beco dos Sapos" aos Canaviais de Catende. Disponível em: www.mte.gov.br/ecosolidaria/prog_becosapos.pdf, acesso em 20/Out/2008.

NEVES, Ednalva Felix. Fragilidades e contradições na utopia de uma outra economia. In: Gemma Fajardo García; María José Senent Vidal (orgs). Economía Social: identidad, desafíos y estrategias. Valencia/España: CIRIEC, 2014, p. 289-307. . Percepções sobre as contradições e dificuldades de inserção e sobrevivência dos empreendimentos de economia solidária no mercado. Campinas/SP, 2016. Tese (Doutorado em Desenvolvimento Econômico). Universidade Estadual de Campinas.

PALMIERI Júnior, Valter. Capitalismo e Sociedade de Consumo: uma análise introdutória sobre o consumo e modo de vida na sociedade contemporânea. Campinas/SP, 2012. Dissertação (Mestrado em Desenvolvimento Econômico) Universidade Estadual de Campinas.

PASSOS, Carlos Roberto Martins; NOGAMI, Otto. Princípios de Economia. São Paulo. Editora Pioneira (3a edição), 2000.

PORTAL DO CONSUMO RESPONSÁVEL. Disponível em: http://consumoresponsavel.org.br/. Acesso em 10/Ago/2018.

PORTILHO, Fátima. Sustentabilidade ambiental, consumo e cidadania. São Paulo: Cortez, 2005. 255 p.

SECRETARIA NACIONAL DE ECONOMIA SOLIDÁRIA (SENAES). Atlas da Economia Solidária no Brasil 2005. MTE, SENAES, 2006. Disponível em CD-Room.

Atlas da Economia Solidária 2007. Plataforma online. 2007. Disponível em: http://www.sies.mte.gov.br. Acesso em: 29 jun. 2011.

SINGER, Paul. Economia Solidária: um modelo de produção e distribuição. In: SINGER, Paul; SOUZA, André Ricardo (orgs). A Economia Solidária no Brasil: a autogestão como resposta ao desemprego. São Paulo. Contexto, 2000 (p. 11-28). . Introdução a Economia Solidária. São Paulo: Fundação Perseu Abramo, 2002. 
Artigo | Os desafios para a economia solidária em uma sociedade do consumo (NEVES, Ednalva Felix das; MEZZACAPPA, Gabriela Gonzales; PALMIERI JÚNIOR, Valter)

TIRIBA, Lia. Cultura do trabalho, autogestão e formação de trabalhadores associados na produção: questões de pesquisa. Perspectiva: Revista do Centro de Ciências da Educação. UFSC, Florianópolis. V. 26, n. 1, jan./jun. p. 69-94, 2008.

VEBLEN, Thorstein. A teoria da classe ociosa: um estudo econômico das instituições. São Paulo: Abril Cultural, 1983. 